\title{
Work Disability and the Cost-effectiveness of Drugs to Treat Rheumatic Diseases - Time for a New Dialogue?
}

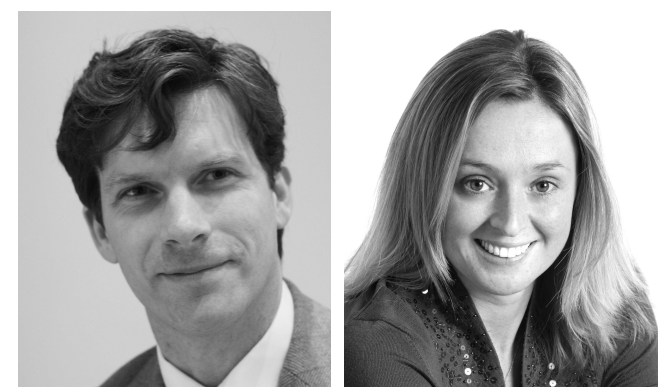

Iragorri, et al, in this edition of The Journal, report a systematic review of the effect of biologics and targeted synthetic drugs on work outcomes in psoriatic arthritis (PsA $)^{1}$. The paper raises several points of interest on the challenges facing investigators in the assessment of work disability and the current methods of judging the cost-effectiveness of treatments for PsA.

Patient-reported work disability has gained increasing traction as an important outcome in rheumatic disease in recent years. Work is important to individuals (both financially and emotionally) and the economy as a whole. Access to appropriate healthcare is just one of the factors that can determine the health of a society (Figure 1). The ability to work can affect an individual's living conditions and social interactions, and has spillover effects on future generations (including educational attainment). Therefore, ensuring that patients can remain at work while handling chronic disease, or return to work as soon as possible after periods of ill health, should be high priorities for those concerned with the health of the nation.

In the context of longterm health conditions such as PsA, work disability may be significant and treatments to improve functional capability can affect not only health-related outcomes but also a patient's ability to undertake productive work. The importance of work for an individual's health and happiness is not a new concept. To Galen of Pergamon (AD 172 ) is attributed the quote, "Employment is nature's physician, and is essential for human happiness," reflecting the central role work plays in the health and well-being of most people. In studies of treatment outcomes important to patients, the ability to work consistently ranks highly, demonstrating that the sentiment is as relevant today as it was in Galen's time ${ }^{2,3}$. As treating clinicians, we have never been better placed to control disease and prevent disability, with the advent of novel treatments that are highly effective. On a societal level, the advent and rapid uptake of highly effective but expensive biologic and targeted synthetic disease-modi- fying antirheumatic drugs (b/tsDMARD) illustrates the need to provide an economic case for the provision of treatments ${ }^{4}$. Such assessments are made through cost-effectiveness analysis, and there have been calls to also include work disability in an assessment of cost-effectiveness ${ }^{5,6}$.

Iragorri, et al, identified placebo-controlled randomized controlled trials (RCT) of adults with PsA that reported a measure of work disability ${ }^{1}$. In total, only 5 trials were judged to be at low risk of bias and were included for analysis (treatments were infliximab, golimumab, certolizumab pegol, ustekinumab, and apremilast). All the treatments assessed improved patient-reported work disability, but the heterogeneity of outcomes used prevented a pooled analysis. The data available for reporting were limited, and of the 5 studies included, only 2 reported the percentage of patients who were employed, and 2 studies did not report on the statistical significance of work productivity ${ }^{7,8}$. The authors conclude that treatment with infliximab, golimumab, certolizumab pegol, ustekinumab, and apremilast improves self-reported work disability and can help inform decisions about which treatments should be reimbursed by quantifying how each treatment reduced productivity costs.

The review highlights the need to improve consistency in outcome measures collected in PsA RCT, including secondary endpoints such as work disability, to aid quantitative comparisons such as metaanalyses. The updated core set of outcome measures to be assessed in PsA RCT now includes work as an outcome (under the umbrella term of Participation $)^{9}$. A variety of measures are used to assess worker productivity in RCT, and 5 have been endorsed by Outcome Measures in Rheumatology Clinical Trials (OMERACT): The Workplace Activity Limitations Scale, the Work Limitations Questionnaire with modified physical demands scale, the Work Ability Index, the Arthritis-specific Work Productivity Survey, and the Work Productivity and Activity Impairment Questionnaire (WPAI) ${ }^{10}$. Efforts are currently under way to evaluate the validity of all outcome

See Biologics and work productivity, page 1124

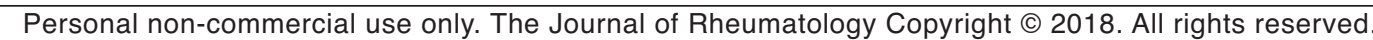




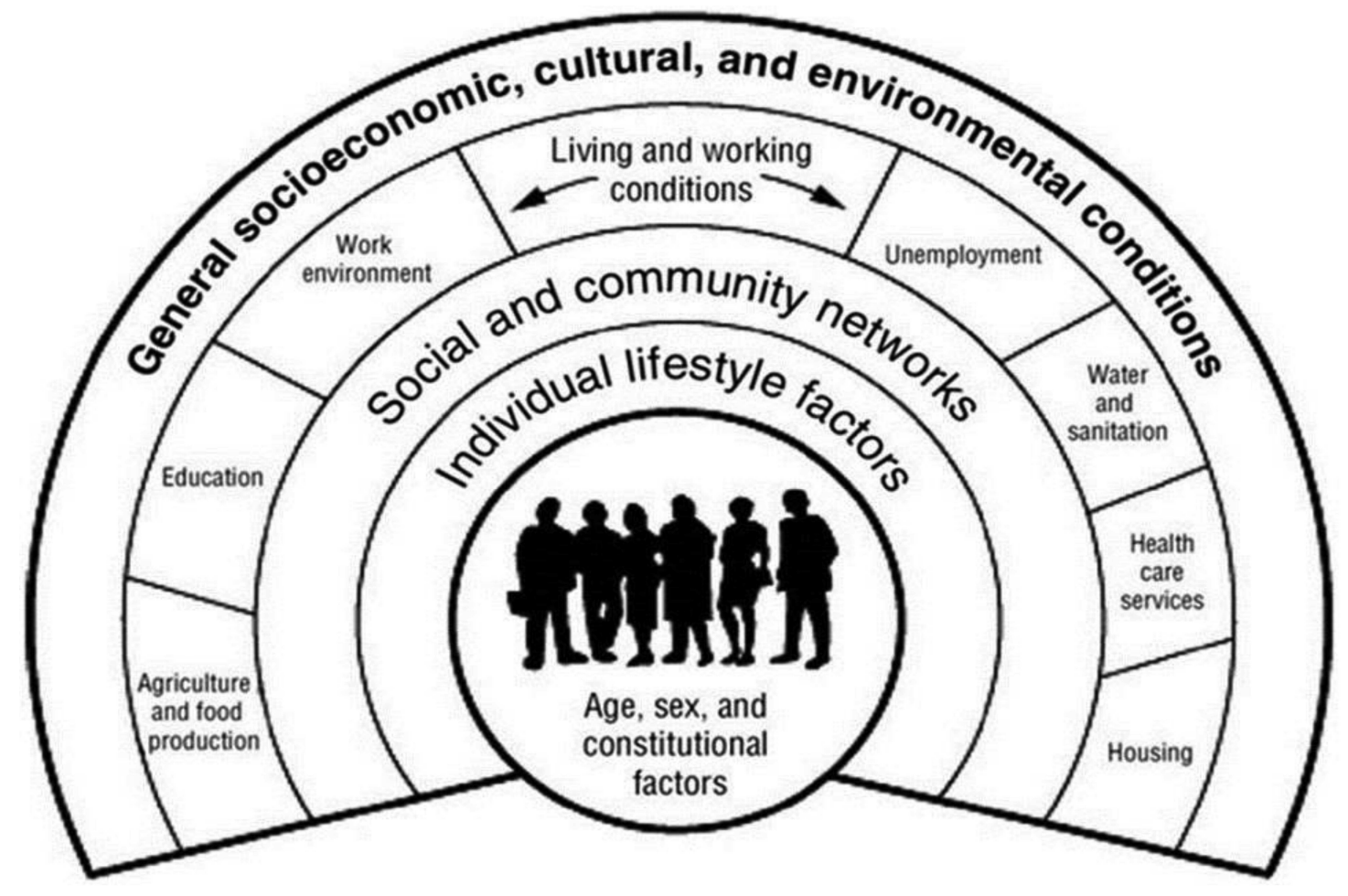

Figure 1. The Dahlgren-Whitehead model. Used with permission: Dahlgren G, Whitehead M. Policies and strategies to promote social equity in health. Stockholm, Sweden: Institute for Futures Studies; 1991.

measures used for the assessment of PsA against the OMERACT filter, to derive a "core set" of measurement instruments for use in trials. Over time, agreement on instruments will result in more consistency across trials and greater facility for comparison between drugs.

In the review by Iragorri, et al, only fully published articles were eligible for inclusion ${ }^{1}$. Quality-of-life measures are often secondary endpoints and are often reported only in conference abstract form; as a result, relevant studies reporting work data may have been missed, introducing reporting bias. By example, the WPAI was collected as a measure of work productivity in the secukinumab trials in PsA and demonstrated improvement in productivity loss ${ }^{11,12}$. The WPAI is one of the few work outcomes with a PsA-specific estimate of the minimal important difference ${ }^{13}$. Observational cohort and registry studies were also excluded in the review by Iragorri, et $a l^{1}$. Nonrandomized studies can provide important data over longer time frames, in a more real-world setting that complements RCT data. Data from the British Society of Rheumatology Biologics Registry ${ }^{14}$, the Danish Biologics Registry ${ }^{15}$, and a 2-year UK multicenter study of work disability in PsA ${ }^{16}$ each support the view that work disability is prevalent among patients with PsA and is improved with better disease control, particularly with bDMARD.

There seems little debate that we should supplement our understanding of the cost-effectiveness of drugs with data on work disability. To not do so underestimates the societal benefit of longterm, effective disease control and prevention of damage and irreversible disability. So the question for clinicians, health economists, and healthcare commissioners is how we reflect employment in an assessment of the cost-effectiveness of competing alternatives and how we can use the data reported by Iragorri, et al in this edition of The Journal to inform such assessments ${ }^{1}$. Do the data support reimbursement decisions, where healthcare resources are scarce, in the absence of any quantitative comparisons of work disability between alternative treatments? The data presented do not include any direct comparison between drugs; therefore, they are not suitable for making comparative effectiveness judgments, including on work productivity. However, the paper raises a number of issues that are relevant to the broader discussion of how we can incorporate work productivity (and disability prevention) into the assessment of high-cost drugs in chronic diseases such as PsA.

Iragorri and colleagues raise an important point regarding the challenge of including work in assessments of cost-effectiveness without indirectly penalizing those who do not work (or are not in paid employment) ${ }^{1}$. So how can we move forward without indirectly exacerbating inequalities? Perhaps clinicians, as patient advocates and those who most clearly see how effective amelioration of chronic inflammatory disease enables patients to work, should promote employment to be considered in healthcare. It remains to be deter-

Personal non-commercial use only. The Journal of Rheumatology Copyright @ 2018 . All rights reserved. 
mined how incorporating work into cost-effectiveness assessments can be achieved without penalizing those in nonpaid work (such as childcare) and those who are not in the paid labor force. Perhaps it can be done by taking a population-level view of disease cost and work disability, factoring work disability into country-specific cost-effectiveness valuations.

Iragorri, et al also emphasize the important issue of perspective for economic analyses ${ }^{1}$. For some national healthcare decision makers, the perspective is restricted to costs pertaining to the healthcare service, and outcomes are strictly health outcomes. Work disability has implications for an individual's health-related quality of life but also affects a broader sense of well-being. Many of the costs of work disability also fall outside the healthcare sector. Inclusion of these wider societal effects of treatment poses challenges, not only in determining how to include them but also in how the implications for reimbursement on budgets are consolidated across sectors.

The systematic review by Iragorri, et al in this edition of The Journal may not tell which drug is most effective at reducing work disability in PsA, but taking a broader view, should accelerate the dialogue on cost-effectiveness valuations in chronic disease in countries with nationalized healthcare systems. Local payers may not see the payoff of longterm high-cost drugs preventing work disability, but prevention of disability may resonate with payers in health and social care at the government level, particularly those taking a broader perspective.

WILLIAM TILLETT, $\mathrm{MBChB}, \mathrm{BSc}, \mathrm{PhD}, \mathrm{MRCP}$, Royal National Hospital for Rheumatic Diseases; and

Department of Pharmacy and

Pharmacology, University of Bath, Bath;

LAURA BOJKE, BA (Hons), MSc and PhD,

Centre for Health Economics,

University of York, York, UK.

Address correspondence to W. Tillett, Royal National Hospital for Rheumatic Diseases, Rheumatology, Upper Borough Walls, Bath BA1 1RL, UK. E-mail: w.tillett@nhs.net

\section{REFERENCES}

1. Iragorri N, Hofmeister M, Spackman E, Hazlewood G. The effect of biologic and targeted synthetic drugs on work- and productivity-related outcomes for patients with psoriatic arthritis: a systematic review. J Rheumatol 2018;45:1124-30.

2. Gossec L, de Wit M, Kiltz U, Braun J, Kalyoncu U, Scrivo R, et al. A patient-derived and patient-reported outcome measure for assessing psoriatic arthritis: elaboration and preliminary validation of the Psoriatic Arthritis Impact of Disease (PsAID) questionnaire, a 13-country EULAR initiative. Ann Rheum Dis 2014;73:1012-9.
3. Dures E, Hewlett S, Lord J, Bowen C, McHugh N, Group PS, et al. Important treatment outcomes for patients with psoriatic arthritis: a multisite qualitative study. Patient 2017;10:455-62.

4. Nurmohamed MT, Dijkmans BA. Efficacy, tolerability and cost effectiveness of disease-modifying antirheumatic drugs and biologic agents in rheumatoid arthritis. Drugs 2005;65:661-94.

5. Shepard DS. Chapter 4. In: Cost-effectiveness in health and medicine. Gold MR, Siegel JE, Russell LB, Weinstein MC, editors. New York: Oxford University Press; 1996.

6. Bojke L, Spackman E, Hinde S, Helliwell P. Capturing all of the costs in NICE appraisals: the impact of inflammatory rheumatic diseases on productivity. Rheumatology 2012;51:210-5.

7. Kavanaugh A, Antoni C, Mease P, Gladman D, Yan S, Bala M, et al. Effect of infliximab therapy on employment, time lost from work, and productivity in patients with psoriatic arthritis. J Rheumatol 2006;33:2254-9.

8. Kavanaugh A, Gladman D, van der Heijde D, Purcaru O, Mease P. Improvements in productivity at paid work and within the household, and increased participation in daily activities after 24 weeks of certolizumab pegol treatment of patients with psoriatic arthritis: results of a phase 3 double-blind randomised placebo-controlled study. Ann Rheum Dis 2015;74:44-51.

9. Orbai AM, de Wit M, Mease P, Shea JA, Gossec L, Leung YY, et al. International patient and physician consensus on a psoriatic arthritis core outcome set for clinical trials. Ann Rheum Dis 2017; 76:673-80.

10. Beaton DE, Dyer S, Boonen A, Verstappen SM, Escorpizo R, Lacaille DV, et al. OMERACT filter evidence supporting the measurement of at-work productivity loss as an outcome measure in rheumatology research. J Rheumatol 2016;43:214-22.

11. Strand V, FitzGerald O, Coates L, Walsh J, Cañete J, Bhosekar V, et al. FRI0521 Secukinumab provides sustained improvements in work productivity and health related quality of life in patients with active psoriatic arthritis: 2-year results from future 1 and future 2. Ann Rheum Dis 2017;76 Suppl 2:688.

12. Rahman P, Strand V, McInnes IB, Marzo-Ortega H, Dokoupilová E, Churchill M, et al. THU0433 Secukinumab improves physical function, quality of life, fatigue and work productivity in patients with active psoriatic arthritis in future 2, a phase 3 trial. Ann Rheum Dis 2015;74 Suppl 2:356.

13. Tillett W, Shaddick G, Boyce B, McHugh NJ, editors. Validity of the Wpai-SHP in psoriatic arthritis and estimation of the minimally important difference [abstract]. Arthritis Rheumatol 2017; 69 Suppl 10:2039.

14. Verstappen SM, Watson KD, Lunt M, McGrother K, Symmons DP, Hyrich KL. Working status in patients with rheumatoid arthritis, ankylosing spondylitis and psoriatic arthritis: results from the British Society for Rheumatology Biologics Register. Rheumatology 2010;49:1570-7.

15. Kristensen LE, Jorgensen TS, Christensen R, Gudbergsen H, Dreyer L, Ballegaard C, et al. Societal costs and patients' experience of health inequities before and after diagnosis of psoriatic arthritis: a Danish cohort study. Ann Rheum Dis 2017;76:1495-501.

16. Tillett W, Shaddick G, Jobling A, Askari A, Cooper A, Creamer P, et al. Effect of anti-TNF and conventional synthetic disease-modifying anti-rheumatic drug treatment on work disability and clinical outcome in a multicentre observational cohort study of psoriatic arthritis. Rheumatology 2017;56:603-12.

J Rheumatol 2018;45:1075-7; doi:10.3899/jrheum.180197 